\title{
Impacts of intellectual capital on process innovation and mass customisation capability: Direct and mediating effects
}

\begin{abstract}
This paper presents an empirical survey study. We propose a model to examine the individual and joint effects of the three components of intellectual capital (i.e., human, social, and structural capital) on process innovation and mass customisation (MC) capability. The hypotheses are empirically tested using structural equation modelling and data collected from 645 manufacturing plants in 10 countries/regions. The results show that human and social capital are positively associated with structural capital. Human capital directly improves both process innovation and MC capability. The direct effect of social capital on MC capability and that of structural capital on process innovation are positive and significant. Moreover, process innovation is positively associated with MC capability. In addition, we find that structural capital mediates human and social capital's effects on process innovation, and process innovation mediates human and structural capital's effects on MC capability. This study contributes to the literature by providing insights into how human, social, and structural capital jointly improve process innovation and MC capability, as well as how the different types of knowledge residing in a manufacturer affect MC capability development.
\end{abstract}

Keywords: intellectual capital, process innovation, mass customisation 


\section{Introduction}

Mass customisation (MC) has been viewed as an important strategy for manufacturing firms to improve performance and obtain competitive advantages in dynamic and uncertain business environments (Liu, Shah, and Schroeder 2012; Liu, Shah, and Babakus 2012; Choi and Guo 2017). Hence, the development of MC capability, which refers to the ability to offer a reliable and high volume of different product options for a relatively large market without substantial trade-offs in cost, delivery, and quality (Zhang et al. 2015; Huang, Kristal, and Schroeder 2008), has become a key challenge for manufacturing firms in both developing and developed countries (Salvador, de Holan, and Piller 2009; Rungtusanatham and Salvador 2008). Researchers have argued that innovative process designs such as postponement, process modularity, and integration ( Tu et al. 2004; Liu, Shah, and Schroeder 2012; Da Silveira, Borenstein, and Fogliatto 2001) are critical for MC capability development, and they have found that innovation is positively associated with MC capability (Wang, Wang, and Zhao 2015; Wang et al. 2016; Jitpaiboon et al. 2013). However, there is limited empirical evidence on the roles played by process innovation in MC capability development. In addition, knowledge has been viewed as an important enabler for MC (Da Silveira, Borenstein, and Fogliatto 2001). Researchers have linked various knowledge management practices, such as internal and external learning (Huang, Kristal, and Schroeder 2008), information processing capability (Trentin, Forza, and Perin 2012), absorptive capacity (Zhang et al. 2015), and knowledge utilisation (Wang, Wang, and Zhao 2015), with MC capability. However, less attention has been paid to the impacts of different types of knowledge on MC capability.

Intellectual capital collectively refers to the stock of knowledge within firms (Lee 2011; Bontis 1998). From the perspective of where the knowledge resides, intellectual capital can be conceptualized into three components: human capital (i.e., employees' knowledge and skills), social capital (i.e., social relationships and interactions among employees), and structural capital (i.e., operating procedures and systems) (Menor, Kristal, and Rosenzweig 2007; Lee, Swink, and Pandejpong 2011; Hsu and Wang 2012). They reflect the knowledge held by individuals, the knowledge residing in social relationships and networks, and the knowledge stored within organisational processes, structures, and systems, respectively (Subramaniam and Youndt 2005; Youndt, Subramaniam, and Snell 2004). Empirical evidence exists that intellectual capital is positively associated with performance (Bontis 1998; Hsu and Wang 2012) and product innovation (Hsu and Sabherwal 2012; Menor, Kristal, and Rosenzweig 2007). Researchers have found that the three intellectual capital components 
play different roles in influencing the technical success of manufacturing process innovation projects (Lee, Swink, and Pandejpong 2011) and various innovation capabilities (Subramaniam and Youndt 2005), and that they are interrelated (Kang and Snell 2009; Youndt, Subramaniam, and Snell 2004). However, few studies have empirically investigated the mechanisms through which human, social, and structural capital jointly influence MC capability.

The objective of this study is to empirically investigate the impacts of intellectual capital on process innovation and MC capability development. This study addresses two research questions. First, how do human, social, and structural capital jointly affect process innovation and MC capability? Second, what are the roles played by process innovation in MC capability development?

\section{Literature review and research hypotheses}

\subsection{Intellectual capital}

Human, social, and structural capital reflect three different kinds of knowledge that a firm can leverage to create competitive advantages (Bontis 1998; Lee, Swink, and Pandejpong 2011). Human capital refers to the expertise, skills, and abilities residing in and utilised by individuals (Kang and Snell 2009). The knowledge embedded in the mind of employees enables them not only to perform their jobs but also to absorb and create new knowledge (Zhang et al. 2015). Employees' knowledge in a specific domain and skills and expertise in their respective jobs allow them to adjust current products and processes based on changes in customer preferences and market environments (Lee 2011; Zhang, Guo, and Zhao 2016). Multi-skilled employees with generalized experiences can develop new knowledge by synthesising diversified knowledge domains, leading to new products and processes (Hsu and Wang 2012). Social capital refers to the actual and potential knowledge embedded within, available through, and utilised by interactions among individuals and their networks of relationships (Nahapiet and Ghoshal 1998). It reflects the knowledge that emerges from formal and informal interactions among employees, which provides a basis for cooperation and a mechanism for knowledge exchange and combination within a firm (Zhang, Lettice, and Zhao 2015). Social capital connects employees and can improve psychological safety (Lee 2011) and the quality, relevance, and timeliness of the information flows within a firm (Adler and Kwon 2002). Frequent and dense social interactions among employees allow them to develop common understandings about knowledge, access and obtain colleagues' private know-how, make joint decisions on knowledge application, and cooperate on 
knowledge creation, which are especially important for absorbing tacit knowledge (Adler and Kwon 2002; Nahapiet and Ghoshal 1998). Structural capital refers to the knowledge stored in and utilised by organisational processes, routines, systems, and manuals (Youndt, Subramaniam, and Snell 2004). It goes beyond specific individuals and their relationships and forms formal procedures or managerial routines for storing and retrieving individual knowledge (Subramaniam and Youndt 2005). Structural capital contains disciplined methods and codified knowledge that arise from established structures and procedures (Lee 2011; Subramaniam and Youndt 2005). In this way, a firm transforms employees' past successful experiences and best practices into standard operating procedures, manuals, archives, and databases that can be shared within the firm, enabling the firm to leverage the knowledge even if the employees leave the firm (Menor, Kristal, and Rosenzweig 2007; Bontis 1998). Hence, structural capital can formalise a firm's operations and improve the efficiency of decision making (Hsu and Wang 2012).

\subsection{Process innovation}

Process innovation refers to the changes in the way a firm produces outputs (Kim, Kumar, and Kumar 2012). Process innovation involves the introduction of new elements and the use of advanced technologies in production processes to improve the speed, quality, efficiency, and reliability of operations (Jayaram, Oke, and Prajogo 2014; Piening and Salge 2015). It requires creative applications of existing knowledge, ideas, methods, and skills (Kim, Kumar, and Kumar 2012). Learning the latest process developments and introducing technologically new or significantly improved production processes more frequently and quickly than competitors can generate unique operational capabilities (Kim, Kumar, and Kumar 2012). They are valuable for improving a firm's competitiveness in the business environments where technologies, customer requirements, market situations, and regulations are changing fast (Piening and Salge 2015; Jayaram, Oke, and Prajogo 2014). A firm's knowledge management systems and collaboration among employees play critical roles in the adoption of new processes, because of the complexity, causal ambiguity, and context-specific nature of process innovation (Piening and Salge 2015; Un and Asakawa 2015).

\subsection{MC capability}

MC aims to provide individually designed products at a reasonable price for a mass market (Da Silveira, Borenstein, and Fogliatto 2001). It requires the alignment between a firm and its customers' needs through agile, flexible, and integrated processes (Salvador, de Holan, and Piller 2009; Liu, Shah, and Schroeder 2012). MC capability can be conceptualized as the ability to aggregate individual customers' requirements into large-batch 
common parts production, to provide customised products at a price comparable to mass production, to reduce total lead times for customised product delivery, and to manage and guarantee the level of quality of every customised product (Tu et al. 2004; Zhang, Lettice, and Zhao 2015; Huang, Kristal, and Schroeder 2008). Researchers have argued that the implementation of $\mathrm{MC}$ requires a firm to transform the marketing, accounting, engineering, manufacturing, and supply chain processes (Rungtusanatham and Salvador 2008), to develop robust process designs such as flexible automation and process modularity (Salvador, de Holan, and Piller 2009), to adopt advanced manufacturing and information technologies and systems, and to create and share knowledge across value chains (Da Silveira, Borenstein, and Fogliatto 2001; Choi and Guo 2017). In addition, empirical evidence exists that MC capability can be developed through the implementation of time-based (Tu, Vonderembse, and Ragu-Nathan 2001) and modularity-based ( $\mathrm{Tu}$ et al. 2004) manufacturing practices, effective process implementation (Huang, Kristal, and Schroeder 2008), functional integration (Trentin, Forza, and Perin 2012; Liu, Shah, and Schroeder 2012), information technologies (Jitpaiboon et al. 2013), and knowledge creation and utilisation (Wang, Wang, and Zhao 2015; Zhang et al. 2015). However, few studies have empirically investigated the joint effects of different types of knowledge and process innovation on MC capability development.

\subsection{Research hypotheses}

The conceptual model and all proposed hypotheses are presented in Figure 1. Organisational knowledge always starts with individuals (Nonaka and Takeuchi 1995). Employees' knowledge and skills form the foundation of a manufacturer's knowledge base and provide inputs for the manufacturer's systems and archives (Youndt, Subramaniam, and Snell 2004). The tacit knowledge embedded in employees can be externalised and stored in structural capital (Nonaka and Takeuchi 1995). A manufacturer's standard operating procedures, processes, and manuals are usually developed by aggregating and formalising employees' past successful experiences and best practices (Reed, Lubatkin, and Srinivasan 2006) and by systemising and combining employees' explicit knowledge (Nonaka and Takeuchi 1995). Human capital also improves a manufacturer's capability to absorb and create new knowledge, which enables the manufacturer to improve structural capital by adapting processes and rules based on changes in market and technological environments (Lee, Swink, and Pandejpong 2011; Subramaniam and Youndt 2005). The conversations and open discussion among employees help them recognise and access each other's personal knowledge and, hence, can improve the quality and quantity of information flows within a 
manufacturer (Adler and Kwon 2002). Social relationships motivate employees to articulate knowledge and share experiences (Nonaka and Takeuchi 1995; Zhang, Guo, and Zhao 2016). Hence, social capital helps a manufacturer externalize tacit knowledge and combine it with explicit knowledge to develop procedures and rules (Nonaka and Takeuchi 1995; Nahapiet and Ghoshal 1998). Social interactions also enable employees to make joint decisions and reach agreement on how to develop databases and improve the efficiency and effectiveness of current processes (Reed, Lubatkin, and Srinivasan 2006). In addition, social capital encourages compliance with rules and regulations and cooperation among employees, and it facilitates the development of self-organising teams, improving structural capital (Nonaka and Takeuchi 1995; Zhang, Lettice, and Zhao 2015). Therefore, we propose the following hypotheses.

\section{H1: Human capital is positively associated with structural capital.}

H2: Social capital is positively associated with structural capital.

$<<<<<<<<<$ Insert Figure 1 about here $>>>>>>>>$

The knowledge residing in employees helps a manufacturer create new knowledge that can be used to develop process innovation and MC capability (Nonaka and Takeuchi 1995). Human capital enables a manufacturer to learn advanced technologies in markets (Kang and Snell 2009). Employees' expertise and skills are important raw materials for process innovation (Lee, Swink, and Pandejpong 2011). Employees who are experts in their fields usually have deep understandings about technological development trajectories and can keep up with the latest process developments (Un and Asakawa 2015; Subramaniam and Youndt 2005). They can help a manufacturer recognise, acquire, and deploy new processes more quickly than competitors. Employees with useful experiences and skills also enlarge a manufacturer's current knowledge domains, which allows the manufacturer to introduce more new processes (Hsu and Wang 2012; Piening and Salge 2015). In addition, skilled employees allow a manufacturer to grasp changes in customer preferences and discover the commonalities among customers, facilitating the manufacturer's ability to modularise products and adjust product designs quickly (Tu et al. 2004; Wang et al. 2016). Researchers argue that MC capability requires a manufacturer to develop unique operational capabilities and adopt advanced technologies (Da Silveira, Borenstein, and Fogliatto 2001; Salvador, de Holan, and Piller 2009). Employees with expertise in their roles enable a manufacturer to implement advanced practices and organisational designs such as integration, postponement, quick response supply, and supply chain collaboration to develop a flexible production system, enhancing MC capability (Liu, Shah, and Schroeder 2012; Tu, Vonderembse, and 
Ragu-Nathan 2001; Trentin, Forza, and Perin 2012; Choi and Guo 2017). Therefore, we propose the following hypotheses.

H3a: Human capital is positively associated with process innovation.

H3b: Human capital is positively associated with MC capability.

Social capital is an indispensable base for employees to share experiences and cooperate in knowledge creation (Nonaka and Takeuchi 1995). Social interactions among employees allow them to develop common objectives and norms and to collaborate across functional boundaries, improving the development and implementation of new processes (Adler and Kwon 2002; Lee 2011). When employees are comfortable discussing problems and issues openly, they are more likely to share and analyse the knowledge about the latest process developments together and explore process designs that are radically different from existing processes without worrying about making mistakes (Adler and Kwon 2002; Kang and Snell 2009). Social capital also enables employees to reach agreement on the expected outcomes of new process development and motivates them to solve problems together, allowing a manufacturer to introduce process innovations frequently (Youndt, Subramaniam, and Snell 2004). Social interactions enable employees in different functions to develop a common understanding of market requirements and the capacity of a production system (Zhang, Lettice, and Zhao 2015). This allows the manufacturer to improve the responsiveness of the production system, which is critical for MC (Da Silveira, Borenstein, and Fogliatto 2001). Moreover, the collaboration and integration among functional departments allow a manufacturer to adapt product and process designs quickly to meet customers' personalised requirements (Liu, Shah, and Schroeder 2012; Jitpaiboon et al. 2013). Cooperative relationships among employees also play an important role in facilitating the absorption of external knowledge (Nahapiet and Ghoshal 1998). The knowledge can be used to align a manufacturer's operations with customers' new requirements, enhancing MC capability (Wang, Wang, and Zhao 2015; Zhang, Guo and Zhao 2016). Therefore, we propose the following hypotheses.

H4a: Social capital is positively associated with process innovation.

H4b: Social capital is positively associated with MC capability.

Structural capital enables a manufacturer to reuse past successful experiences and best practices to guide process innovation, and thus, the manufacturer can introduce new processes frequently (Nonaka and Takeuchi 1995; Subramaniam and Youndt 2005). Employees can also obtain effective references from manuals, archives, and databases to solve problems and develop creative ideas, reducing the costs and lead times of process 
innovation (Lee 2011; Jayaram, Oke, and Prajogo 2014). Standard operating procedures and well-defined processes can formalise a manufacturer's interactions with external partners and the information sharing and collaboration among functional departments, enabling the manufacturer to learn and distribute the knowledge about the latest process developments among employees (Hsu and Wang 2012; Un and Asakawa 2015). In addition, a manufacturer can predict the changes of customer requirements using the knowledge stored in databases, which helps the manufacturer adapt the designs of modules and platforms to swiftly respond to market dynamics (Liu, Shah, and Babakus 2012; Menor, Kristal, and Rosenzweig 2007). Standard operating procedures and manuals can assist employees in making decisions on how to adjust or recombine modules creatively to fulfil customer orders and formalise the interactions with customers, which allows a manufacturer to elicit knowledge from customers effectively (Lee 2011; Wang et al. 2016). Written procedures and rules also ensure that customised products are consistent with quality standards and help a manufacturer reorganise processes quickly and efficiently, enhancing MC capability (Huang, Kristal, and Schroeder 2008; Da Silveira, Borenstein, and Fogliatto 2001). Therefore, we propose the following hypotheses.

H5a: Structural capital is positively associated with process innovation.

H5b: Structural capital is positively associated with MC capability.

Process innovation enables a manufacturer to adopt advanced manufacturing and information technologies and develop new processes that can improve the flexibility and responsiveness of operations, enhancing MC capability (Rungtusanatham and Salvador 2008; Da Silveira, Borenstein, and Fogliatto 2001). Introducing new processes frequently allows a manufacturer to align operations with changing customer requirements, to develop unique capabilities that can reduce costs and lead times associated with customisation, and to benefit from market dynamics (Liu, Shah, and Babakus 2012; Salvador, de Holan, and Piller 2009). In addition, learning new developments on process technologies and designs in an industry enables a manufacturer to incorporate the practices that enhance MC capability, such as modularity, integration, time-based manufacturing, and postponement, into its production systems (Jitpaiboon et al. 2013; Tu, Vonderembse, and Ragu-Nathan 2001; Tu et al. 2004). Therefore, we propose the following hypothesis.

H6: Process innovation is positively associated with MC capability.

\section{Research method}

\subsection{Data}


This study used the data collected from the Global Manufacturing Research Group (GMRG) Round 4.0 Survey conducted between 2007 and 2010 (Olson, Chae, and Sheu 2013; Chae, Olson, and Sheu 2014). The GMRG (www.GMRG.org) is a multi-national community of researchers focusing on the study and improvement of manufacturing supply chains worldwide (Whyback, Wacker, and Sheu 2009). Details regarding the questionnaire development and data collection can be found in Whyback (1997) and Whyback, Wacker, and Sheu (2009). The GMRG developed its database using a common survey instrument for all countries. The questionnaire included two parts (Whybark, Wacker, and Sheu 2009). The first part is the core module, which is about company demographics, manufacturing practices, competitive goals, and internal performance. The second part contains optional modules addressing specific management issues, such as innovation, outsourcing, and manufacturing information systems (Yang, Wacker, and Sheu 2012; Olson, Chae, and Sheu 2013). The measurement items were developed and validated by multiple academics of the research group (Whyback, Wacker, and Sheu 2009). The standardised questionnaires (developed in English) were administrated by the researchers using their native languages (Chae, Olson, and Sheu 2014). Rigorous translating and back-translating were performed to ensure the equivalence of the questionnaires across different countries (Narasimhan and Schoenherr 2012).

Data were collected by individual members of the GMRG, who were requested to take the most appropriate approach and to use the most suitable population frame, depending on the country-specific circumstances (Narasimhan and Schoenherr 2012). Industry associations, trade organization membership lists, and several other sources have been used as a population frame to select manufacturing plants (Whybark 1997). Product descriptions have been used as the industry selection criteria (Whybark 1997). The manufacturing plant was used as the unit of analysis, and the plant managers were the key informants. They were targeted since they were deemed to possess a comprehensive knowledge of the plant's operations (Whybark, Wacker, and Sheu 2009).

Data were collected during on-site visits by researchers or through Internet and mail surveys. A common GMRG data coding program was used to check the completed questionnaires. This program took the survey responses as input (following the format on the English language questionnaire) and produced a common set of data files (Whybark 1997). The data were pooled by a central data administrator, were checked for reliability, consistency, and integrity, and were redistributed to participating researchers. The GMRG collected a total of 645 responses from 10 countries/regions using the innovation optional module. These responses were used in this study. The responses across early and late 
respondents in each country were compared on company demographics using independentsamples $\mathrm{T}$ tests (Schoenherr and Narasimhan 2012). The results reveal that there are no statistically significant differences between early and late respondents, indicating that nonresponse bias is not a serious concern (Schoenherr and Narasimhan 2012). Table 1 shows the demographic information of the plants.

\section{$\langle<<<<<<<<<<<<<<<$ Insert Table 1 about here $>>>>>>>>>>$}

\subsection{Measurement items}

Human capital was measured by four items regarding employees' skills, experiences, and expertise. Four items related to the social interactions and relationships among employees were used to gauge social capital. Structural capital was operationalised as a plant's standard operating procedures, written processes and rules, manuals, and databases using another four items. The items for human, social, and structural capital were developed based on the studies by Subramaniam and Youndt (2005) and Menor, Kristal, and Rosenzweig (2007). Process innovation was measured using four items covering the speed and frequency of new process development and introduction (Parasuraman 2000; Tellis, Prabhu, and Chandy 2009). MC capability was measured by five items regarding high-volume customisation, customisation cost efficiency, customisation responsiveness, and customisation quality (Huang, Kristal, and Schroeder 2008; Liu, Shah, and Babakus 2012). A multiple-item 7-point Likert-type scale (1 = 'strongly disagree'; 7 = 'strongly agree') was employed for all constructs. The scales, which consist of 21 measurement items, are listed in the Appendix. We included research and development (R\&D) investment as a control variable in the analysis, as plants that have invested more in R\&D tend to have higher capabilities for process innovation (Un and Asakawa 2015) and higher MC capability because they have more resources dedicated to developing new products and processes (Wang et al. 2016); it was measured by the percentage of total plant annual sales invested in R\&D. We also controlled for plant size, which was measured by the log-transformation of the number of employees, as large plants may have more resources for new process development (Un and Asakawa 2015) and for investing in adopting advanced manufacturing technologies and practices to pursue multiple operational priorities simultaneously, which may lead to higher MC capability (Huang, Kristal, and Schroeder 2008).

To the best of our knowledge, this research is the first GMRG study using the intellectual capital, process innovation, and MC capability variables. Other variables in the database (i.e., GMRG Round 4.0) have been used to investigate the influences of the production competence measures on the improvement in plant productivity and plant responsiveness 
(Schoenherr and Narasimhan 2012), the effects of integrated supply and environmental management practices on actual and perceived quality (Narasimhan and Schoenherr 2012), the relationships among transaction cost economics variables, governance mechanisms, and manufacturing competitiveness (Yang, Wacker, and Sheu 2012), the impacts of different enterprise resource planning forms on manufacturing organisations (Olson, Chae, and Sheu 2013), and the impacts of data management, IT-enabled planning, and performance management resources on supply chain planning satisfaction and operational performance (Chae, Olson, and Sheu 2014).

To test common method bias, a confirmatory factor analysis (CFA) model was applied to the Harman's single factor model (Podsakoff et al. 2003). The fit indices are as follows: $\chi^{2}(189)=4358.93$, Comparative Fit Index $(\mathrm{CFI})=0.52$, Tucker-Lewis Index (TLI) $=$ 0.47, and Root Mean Square Error of Approximation $($ RMSEA) $=0.19$. These results are below the acceptable values suggested by $\mathrm{Hu}$ and Bentler (1999), suggesting little common method bias. Furthermore, a CFA model (model A) including only traits and one (model B) including both traits and a common method factor were tested. The model fit indices of model B are marginally improved compared to model A, and the loadings of the trait factors in model B are still significant. These suggest that the factor loadings are robust, although a common method factor was included (Podsakoff et al. 2003). The above results show that the common method bias is not a serious concern in this study.

\subsection{Psychometric tests}

We employed Cronbach's alpha and composite reliability to assess construct reliability. The Cronbach's alpha values range from 0.87 to 0.90 , and the composite reliabilities range from 0.91 to 0.92 (Appendix), all of which are above the recommended threshold values of 0.70 , suggesting that the constructs are reliable.

We used average variance extracted (AVE) and CFA to assess the convergent and discriminant validity. The AVE values range from 0.71 to 0.75 (Appendix), which are above the recommended threshold value of 0.50 , thereby demonstrating adequate convergent validity (Fornell and Larcker 1981). In addition, we built a CFA model in which each item was linked to its corresponding construct and the covariance among the constructs was freely estimated. The results are reported in the Appendix. The model fit indices are as follows: $\chi^{2}(179)=610.63, \mathrm{CFI}=0.95, \mathrm{TLI}=0.94$, and RMSEA $=0.061$, which are better than the threshold values recommended by $\mathrm{Hu}$ and Bentler (1999). In addition, all factor loadings are greater than 0.70 , except for one item, which is slightly lower (ranging from 0.682 to 0.915 ) 
and all $\mathrm{t}$ values are greater than 2.0 (ranging from 6.91 to 45.30) (Appendix). The results indicate that convergent validity is ensured.

Using the Fornell-Larcker criteria, discriminant validity is demonstrated when the square root of the AVE of each construct is higher than the correlations between the focal construct and each other construct (Fornell and Larcker 1981). Table 2 shows the means and standard deviations of the constructs, their correlations, and the square roots of the AVEs. A comparison of the correlations and square roots of the AVEs on the diagonal indicates adequate discriminant validity for all constructs (Table 2). We also assessed discriminant validity by building a constrained CFA model for every possible pair of constructs, in which the correlations between the paired constructs were fixed at 1.0. This was compared with the original unconstrained model, in which the correlations between constructs were freely estimated. A significant difference in the chi-square statistics between the constrained and unconstrained models indicates discriminant validity (Fornell and Larcker 1981). The results show that the smallest chi-square difference is 21.18 , which is significant at the $p<0.01$ level, indicating that discriminant validity is ensured.

$\langle<<<<<<<<<<<<$ Insert Table 2 about here $>>>>>>>>>>>>$

\section{Analysis and results}

The hypotheses are tested using structural equation modelling (SEM) with the maximum likelihood estimation method and the AMOS 21.0 program. The results are presented in Figure 2. The model fit indices are $\chi^{2}(213)=711.84, \mathrm{CFI}=0.94$, TLI $=0.93$, and RMSEA $=0.060$, which are acceptable (Hu and Bentler 1999). We find that human $(b=0.49, p<0.01)$ and social $(b=0.25, p<0.01)$ capital significantly improve structural capital (Figure 2), which supports $\mathrm{H} 1$ and $\mathrm{H} 2$. Human capital significantly enhances process innovation $(b=0.39, p<0.01)$ and $\mathrm{MC}$ capability $(b=0.33, \mathrm{p}<0.01)$ (Figure 2), supporting H3a and $\mathrm{H} 3 \mathrm{~b}$. The effect of social capital on process innovation is not significant, but that on MC capability is significant and positive $(b=0.19, \mathrm{p}<0.01)$ (Figure 2). The effect of structural capital on process innovation is significant and positive $(b=0.16, p<0.01)$, but that on MC capability is not significant (Figure 2). Thus, H4b and H5a are supported, but H4a and H5b are not. We also find that process innovation significantly improves MC capability $(b=0.16$, $\mathrm{p}<0.01$ ) (Figure 2), which supports H6. In addition, the findings show that R\&D investment $(b=0.21, p<0.01)$ and plant size $(b=0.11, p<0.01)$ significantly improve process innovation (Figure 2). However, the impacts of plant size and R\&D investment on MC capability are not significant. 
$\langle<<<<<<<<<<<<$ Insert Figure 2 about here $>>>>>>>>>>>$

Based on the results of the SEM analysis, the joint effects of human, social, and structural capital on process innovation and MC capability are assessed by examining the indirect effects of human and social capital on process innovation through structural capital and those of human and structural capital on MC capability through process innovation, with their significance levels determined by the bias-corrected bootstrap method using a 95\% confidence level and employing 5000 samples (Preacher and Hayes 2008). The results show that the bias-corrected $95 \%$ confidence intervals of the indirect effects of human and social capital on process innovation through structural capital are $(0.074,0.222)$ and $(0.122,0.233)$, respectively. The findings indicate that human capital improves process innovation both directly and indirectly through structural capital, and hence, structural capital partially mediates the impact of human capital on process innovation. Social capital only improves process innovation indirectly through structural capital, and hence, its effect on process innovation is fully mediated by structural capital. We also find that the bias-corrected $95 \%$ confidence intervals of the indirect effects of human and structural capital on MC capability through process innovation are $(0.044,0.134)$ and $(0.061,0.142)$, respectively. Because the direct impact of human capital on MC capability is significant, whereas that of structural capital on MC capability is not significant, process innovation partially mediates the impact of human capital on MC capability and fully mediates the impact of structural capital on MC capability.

\section{Discussion}

We find that human capital enhances MC capability both directly and indirectly through process innovation. The results are consistent with existing findings that human capital is a critical resource for firms to develop capabilities (Kang and Snell 2009; Lee, Swink, and Pandejpong 2011; Menor, Kristal, and Rosenzweig 2007). Human capital reflects the knowledge residing in employees, such as specialised technological skills and expertise and generalised experiences about markets and customers (Lee 2011). The knowledge can affect MC capability in two ways. First, it enables a manufacturer to develop new knowledge, which can be applied to improve MC capability. Second, it can be applied to develop new processes based on new customer requirements (Piening and Salge 2015; Zhang et al. 2015). Innovative process designs enable manufacturers to modularise processes and postpone customisation to the downstream of a supply chain, enhancing MC capability ( Tu et al. 2004; Wang et al. 2016). We also find that human capital improves process innovation both directly 
and indirectly through structural capital. Human capital allows a manufacturer to develop new processes quickly and efficiently by leveraging employees' know-how (Becker 1994). Employees' knowledge on best practices and past successful experiences are critical inputs for organisational processes, procedures, and databases (Lee, Swink, and Pandejpong 2011). Hence, human capital also allows a manufacturer to develop structural capital, which improves process innovation by facilitating cross-functional collaboration and problem solving (Tellis, Prabhu, and Chandy 2009). Investments in human capital raise individuals' observed earnings (Becker 1994). The findings indicate that human capital also enables a manufacturer to create organisational knowledge and develop MC capability (Nonaka and Takeuchi 1995). Hence, a manufacturer can benefit from motivating employees to invest in human capital such as training and education. Therefore, we suggest that managers create organisational environments and systems to support creative individuals, amplify and crystallise the knowledge created by them (Nonaka and Takeuchi 1995), and implement the knowledge to improve existing or design new processes and products (Wang, Wang, and Zhao 2015; Zhang et al. 2015).

The results reveal that social capital directly improves MC capability, whereas it improves process innovation only indirectly through structural capital. These results are consistent with existing empirical evidence that collaborative relationships among functional departments are positively associated with MC capability (Liu, Shah, and Schroeder 2012; Trentin, Forza, and Perin 2012). These results are also consistent with the argument that social capital enables employees to develop new knowledge that improves innovation (Adler and Kwon 2002; Nahapiet and Ghoshal 1998). Social capital reflects the knowledge embedded within the networks of social relationships. It allows employees to find the colleagues who have the knowledge and skills that are critical to solve problems and adjust operations to fulfil customer requirements quickly, and it helps them collaborate on aligning products and processes with changes in markets (Reed, Lubatkin, and Srinivasan 2006). Hence, social capital can improve the flexibility, speed, and responsiveness of operations, enhancing MC capability (Zhang, Lettice, and Zhao 2015; Hsu and Wang 2012). However, although social capital promotes knowledge combination and exchange (Nahapiet and Ghoshal 1998), it usually cannot be directly applied to develop or deploy new processes, because it is not technology-oriented. Hence, the direct effect of social capital on process innovation is not significant. Social capital enables employees to openly discuss their experiences and ideas on new process development, thus externalising their technological know-how and skills. This helps a manufacturer develop processes and databases that can 
formalise and guide new process development, enhancing the speed and frequency of process innovation (Menor, Kristal, and Rosenzweig 2007; Kim, Kumar, and Kumar 2012). Hence, structural capital mediates social capital's effects on process innovation. Social capital can construct a field where tacit knowledge can be created (Nonaka and Takeuchi 1995). The findings indicate that a manufacturer can benefit from this knowledge in two ways. First, the manufacturer can improve operational capabilities by directly applying the knowledge. Second, the manufacturer can develop processes and procedures to help employees articulate the tacit knowledge into explicit concepts that improve process innovation (Nonaka and Takeuchi 1995). Therefore, we suggest researchers consider the conversion between tacit and explicit knowledge when investigating the effects of social capital.

We find that structural capital directly enhances process innovation, whereas it only improves MC capability indirectly through process innovation. These results are compatible with existing empirical evidence that structural capital is positively associated with innovation (Lee, Swink, and Pandejpong 2011; Subramaniam and Youndt 2005) and that its effects on performance are mediated by dynamic capability (Hsu and Wang 2012). Structural capital reflects the knowledge stored in the organisational repository. It enables a manufacturer to keep and reuse employees' technological skills and know-how, and it allows a manufacturer to share and distribute best practices and disciplined methods to everyone in its organisation and to reapply these practices and methods in process innovation, improving the speed and frequency of new process introduction (Parasuraman 2000; Youndt, Subramaniam, and Snell 2004; Zhang et al. 2015). Structural capital standardises a manufacturer's operations, and employees are required to follow established procedures and rules. MC requires a manufacturer to respond to customer requirements by adapting processes and products swiftly and efficiently (Da Silveira, Borenstein, and Fogliatto 2001). It is likely that customers' requirements cannot be fulfilled by a manufacturer's current operating procedures and written processes, which are developed based on past experiences. It may also take some time for a manufacturer to adjust or develop new structural capital. Hence, the direct effect of structural capital on MC capability is not significant. Structural capital helps a manufacturer develop new processes with high flexibility and responsiveness, which can improve MC capability. Hence, process innovation mediates structural capital's impact on MC capability. Structural capital can expand individual knowledge, thus enabling a manufacturer to reuse existing resources creatively to develop new processes (Nonaka and Takeuchi 1995). During process innovation, structural capital can be used to produce new organisational knowledge through internalisation and combination, which enhances 
operational capabilities (Zhang, Guo and Zhao 2016). Therefore, we suggest that managers integrate the practices that facilitate knowledge creation into new process development systems.

\section{Conclusions}

This study contributes to the MC literature by linking intellectual capital and process innovation with MC capability development. It provides empirical evidence that intellectual capital improves MC capability both directly and indirectly through process innovation, enhancing current understanding on how to develop MC capability (Huang, Kristal, and Schroeder 2008; Jitpaiboon et al. 2013; Wang et al. 2016). The results also clarify the mechanisms through which the knowledge held by individuals, residing in social relationships and networks, and stored within organisational structures affects MC capability, providing insights into the impacts of knowledge management on MC capability development (Trentin, Forza, and Perin 2012; Wang, Wang, and Zhao 2015; Zhang et al. 2015). This study thus reveals that researchers should explicitly consider the impacts of different types of knowledge in MC research. In addition, we find that process innovation not only directly enhances but also mediates human and structural capital's effects on MC capability, improving existing knowledge on the relationships between process innovation and MC capability (Jitpaiboon et al. 2013; Wang et al. 2016). Hence, we suggest that researchers consider the impacts of human and social capital and process innovation simultaneously to capture their synergic effects on MC capability development.

This study contributes to the intellectual capital literature by providing insights into the individual and joint effects of human, social, and structural capital on process innovation and MC capability (Reed, Lubatkin, and Srinivasan 2006; Lee, Swink, and Pandejpong 2011). We find that human capital has direct and positive effects on both process innovation and MC capability, whereas social capital only improves MC capability and structural capital only improves process innovation directly. These results provide empirical evidence on the distinctive effects of the components of intellectual capital on innovation and organisational capabilities, enhancing existing knowledge on the impacts of intellectual capital on performance outcomes (Reed, Lubatkin, and Srinivasan 2006; Kang and Snell 2009). In addition, the results show that human and social capital increase structural capital, and structural capital mediates human and social capital's effects on process innovation. These findings improve current understanding on the interrelationships among human, social, and structural capital and their joint effects on innovation (Youndt, Subramaniam, and Snell 2004; 
Subramaniam and Youndt 2005; Lee 2011). Hence, researchers should consider both the direct and mediating effects of the components of intellectual capital on performance outcomes.

This study also provides guidelines for managers on how to leverage intellectual capital to improve innovation and develop organisational capabilities. First, we suggest that manufacturers invest in human, social, and structural capital for process innovation and MC capability development. Manufacturers could hire employees who are experts in their respective jobs. Training programs could be designed to share manufacturers' best practices among and distribute new technological and market knowledge to employees. Job rotation could be implemented to enrich employees' experiences and develop their skills. We also suggest manufacturers organise formal and informal social events such as workshops, seminars, and conferences for employees to interact with and build relationships among each other. Manufacturers could create lateral communication channels and organise crossfunctional meetings for employees in different departments to exchange information. Multifunctional teams could be created to facilitate internal collaboration on new product and process development. An organisational culture that values goodwill, benevolence, collaboration, and openness could also be developed. In addition, we suggest that manufacturers design standard operating procedures and written rules and processes based on best practices, past experiences, and employees' knowledge and expertise. Moreover, manufacturers could invest in developing information systems and databases to store the lessons learned from the manufacturers' innovation projects and their outcomes and from employees' suggestions and ideas on new product and process designs. Manuals could be created to guide employees' decision making and daily work. Managers should be aware that human, social, and structural capital have different direct impacts on process innovation and MC capability. Manufacturers should focus on human and structural capital to improve process innovation, whereas they should emphasise human and social capital for developing MC capability.

Second, we suggest that managers take the interrelationships among human, social, and structural capital into consideration when making decisions related to knowledge management, process innovation, and MC. Managers should use the knowledge residing in employees and embedded in networks of relationships to develop standard operating procedures, written processes and rules, manuals, and operational systems. Structural capital also mediates human and social capital's effects on process innovation. Hence, to capture the synergic effects of the components of intellectual capital on process innovation, we suggest 
that managers invest in developing human, social, and structural capital at the same time. In addition, we find that process innovation mediates the impacts of human and structural capital on MC capability. Therefore, to fully reap the benefits of human and structural capital on MC capability development, we suggest that managers invest in process innovation simultaneously. For example, managers could frequently interact with external knowledge sources such as suppliers, competitors, customers, and universities and research institutes to learn the latest technological developments. Employees could be encouraged and rewarded for their suggestions and ideas on process innovation. Manufacturers could also increase the R\&D investment dedicated to new process development.

Although this study makes significant theoretical and practical contributions, it has limitations that open avenues for future research. First, this study focuses on a manufacturer's internal knowledge stock. Researchers argue that knowledge obtained from external partners also affects process innovation and MC capability (Un and Asakawa 2015; Huang, Kristal, and Schroeder 2008). Future studies could explore the joint effects of intellectual capital and knowledge obtained from external partners on innovation and MC capability development. Second, this study focuses on the social capital among internal employees. Researchers argue that knowledge may also be embedded in a firm's external relationships or networks (Bontis 1998; Reed, Lubatkin, and Srinivasan 2006; Lee 2011). Future studies could examine how external social capital affects the impacts of human, internal social, and structural capital on performance outcomes. Third, this study conceptualises human capital as employees' skills and capabilities. Becker (1994) measures human capital by the investments in the activities that influence people's future monetary and psychic income. Future studies could investigate the impacts of different kinds of investments in human capital, such as on-the-job training and schooling, on a manufacturer's performance and capabilities. Fourth, owing to the variety of survey administrations and the unavailability of the initial sample population in some countries, it is unfortunately not possible to calculate an overall response rate (Schoenherr and Narasimhan 2012), which is a limitation of this study. 


\section{References}

Adler, P.S., and S. Kwon. 2002. "Social capital: Prospects for a new concept." Academy of Management Review 27 (1):17-40.

Becker, G.S. 1994. Human capital: A theoretical and empirical analysis, with special reference to education ( $3^{\text {rd }}$ edition) The University of Chicago Press: Chicago.

Bontis, N. 1998. "Intellectual capital: An exploratory study that develops measures and models." Management Decision 36 (2):63-76.

Chae, B. D. Olson, and C. Sheu. 2014. " The impact of supply chain analytics on operational performance: A resource-based view." Inernational Journal of Production Research 52(16):4695-710.

Choi, T., and S. Guo. 2017. "Responsive supply in fashion mass customisation systems with consumer returns." International Journal of Production Research DOI: 10.1080/00207543.2017.1292065.

Da Silveira, G., D. Borenstein, and F.S. Fogliatto. 2001. "Mass customization: Literature review and research directions." International Journal of Production Economics 72 (1):7-13.

Fornell, C. and D. F. Larcker. 1981. "Evaluating structural equation models with unobservable variables and measurement errors". Journal of Marketing Research 18(1): 39-50.

Hsu, I., and R. Sabherwal. 2012. "Relationship between intellectual capital and knowledge management: An emprical investigation." Decision Sciences 43 (3):489-524.

Hsu, L., and C. Wang. 2012. "Clarifying the effect of intellectual capital on performance: The mediating role of dynamic capability." British Journal of Management 23 (2):179-205.

Hu, L. and P. M. Bentler. 1999. "Cutoff criteria for fit indices in covariance structure analysis: Conventional criteria versus new alternatives". Structural Equation Modelling 6(1):155.

Huang, X., M.M. Kristal, and R.G. Schroeder. 2008. "Linking learning and effective process implementation to mass customisation capability." Journal of Operations Management 26 (6):714-29.

Jayaram, J., A. Oke, and D. Prajogo. 2014. "The antecedents and consequences of product and process innovation strategy implementation in Australian manufacturing firms." International Journal of Production Research 52 (15):4424-39. 
Jitpaiboon, T., D.D. Dobrzykowski, T.S. Ragu-Nathan, and M. A. Vonderembse. 2013. "Unpacking IT use and integration for mass customisation: A service-dominant logic view." International Journal of Production Research 51 (8):2527-47.

Kang, S., and S.A. Snell. 2009. "Intellectual capital architectures and ambidextrous learning: A framework for human resource management." Journal of Management Studies 46 (1):65-92.

Kim, D., V. Kumar, and U. Kumar. 2012. "Relationship between quality management practices and innovation." Journal of Operations Management 30 (4):295-315.

Lee, J.Y. 2011. "Incremental innovation and radical innovation: The impacts of human, structural, social and relational capital elements." Michigan State University.

Lee, J.Y., M. Swink, and T. Pandejpong. 2011. "The role of woker expertise, information sharing quality, and psychological safety in manufacturing process innovation: An intellectual capital perspective." Production and Operations Management 20 (4):55670.

Liu, G., R. Shah, and E. Babakus. 2012. "When to mass customise: The impact of environmental uncertainty." Decision Sciences 43 (5):851-87.

Liu, G., R. Shah, and R.G. Schroeder. 2012. "The relationships among functional integration, mass customisation, and firm performance." International Journal of Production Research 50 (3):677-90.

Menor, L.J., M.M. Kristal, and E.D. Rosenzweig. 2007. "Examining the influence of intellectual capital on capabilities and performance." Manufacturing \& Service Operations Management 9 (4):559-78.

Nahapiet, J., and S. Ghoshal. 1998. "Social capital, intellectual capital, and the organisational advantage." Academy of Management Review 23 (2):242-66.

Narasimhan, R., and T. Schoenherr. 2012. "The effects of integrated supply management practices and environmental practice on relative competitive quality advantage." International Journal of Production Research 50 (4):1185-201.

Nonaka, I. and H. Takeuchi. 1995. The knowledge-creating company: How Japanese companies create the dynamics of innovation Oxford University Press: New York.

Olson, D.L., B.K. Chae, and C. Sheu. 2013. "Relative impact of different ERP forms on manufacturing organisations: An exploratory analysis of a global manufacturing survey." International Journal of Production Research 51(5): 1520-34.

Parasuraman, A. 2000. “Technology Readiness Index (TRI) a multiple-item scale to measure readiness to embrace new technologies." Journal of Service Research 2(4):307-20. 
Piening, E.P., and T.O. Salge. 2015. "Understanding the antecedents, contingencies, and performance implications of process innovation: A dynamic capabilities perspective." Journal of Product Innovation Management 32 (1):80-97.

Podsakoff, P. M., S. B. Mackenzie, J. Y. Lee, and N. P. Podsakoff. 2003. "Common method biases in behavioral research: A critical review of the literature and recommended remedies". Journal of Applied Psychology 88(5):879-903.

Preacher, K., and A. Hayes. 2008. "Asymptotic and resampling strategies for assessing and comparing indirect effects in multiple mediator models". Behavior Research Methods, 40(3):879-91.

Reed, K.K., M. Lubatkin, and N. Srinivasan. 2006. "Proposing and testing an intellectual capital-based view of the firm." Journal of Management Studies 43 (4):867-93.

Rungtusanatham, M.J., and F. Salvador. 2008. "From mass production to mass customisation: Hindrance factors, structural inertia, and transition hazard." Production and Operations Management 17 (3):385-96.

Salvador, F., P.M. de Holan, and F. Piller. 2009. "Cracking the code of mass customization." MIT Sloan Management Review 50 (3):71-8.

Schoenherr, T., and R. Narasimham. 2012. "The fit between capabilities and priorities and its impact on performance improvement: Revisiting and extending the theory of production competence." International Journal of Production Research 50 (14):375575.

Subramaniam, M., and M.A. Youndt. 2005. "The influence of intellectual capital on the types of innovative capabilties." Academy of Management Journal 48 (3):450-63.

Tellis, G. J., J. C. Prabhu, and R. K. Chandy. 2009. "Radical innovation across nations: The preeminence of corporate culture.” Journal of Marketing 73(1): 3-23.

Trentin, A., C. Forza, and E. Perin. 2012. "Organisation design strategies for mass customisation: An information-processing-view perspective." International Journal of Production Research 50 (14):3860-77.

Tu, Q., M.A. Vonderembse, and T.S. Ragu-Nathan. 2001. "The impact of time-based manufacturing practices on mass customization and value to customer." Journal of Operations Management 19 (2):201-17.

Tu, Q., M.A. Vonderembse, T.S. Ragu-Nathan, and B. Ragu-Nathan. 2004. "Measuring modularity-based manufacturing practices and their impact on mass customisation capability: A customer-driven perspective." Decision Sciences 35 (2):147-68. 
Un, C.A., and K. Asakawa. 2015. "Types of R\&D collaborations and process innovation: The benefit of collaborating upstream in the knowledge chain." Journal of Product Innovation Management 32 (1):138-53.

Wang, Q., Z. Wang, and X. Zhao. 2015. "Strategic orientations and mass customisation capability: the moderating effect of product life cycle." International Journal of Production Research 53 (17):5278-95.

Wang, Z., M. Zhang, H. Sun, and G. Zhu. 2016. "Effects of standardization and innovation on mass customisation: An empirical investigation." Technovation 48/49:79-86.

Whybark, C. 1997. "GMRG survey research in operations management." International Journal of Operations \& Production Management 17 (7):686-96.

Whybark, C., J. Wacker, and C. Sheu. 2009. "The evolution of an international academic manufacturing survey." Decision Line May 2009:17-9.

Yang, C., J.G. Wacker, and C. Sheu. 2012. "What makes outsourcing effect? A transactioncost economics analysis." International Journal of Production Research 50(16):446276.

Youndt, M.A., M. Subramaniam, and S.A. Snell. 2004. "Intellectual capital profiles: An examination of investments and returns." Journal of Management Studies 41 (2):33561.

Zhang, M., F. Lettice, and X Zhao. 2015. "The impact of social capital on mass customisation and product innovation capabilities." International Journal of Production Research 53(17):5251-64.

Zhang, M., H. Guo, and X. Zhao. 2016. "Effects of social capital on operational performance: Impacts of servitisation." International Journal of Production Research DOI: 10.1080/00207543.2016.1246764.

Zhang, M., X. Zhao, M. Lyles, and H. Guo. 2015. "Absorptive capacity and mass customisation capability." International Journal of Operations \& Production Management 35 (9):1275-94. 
Appendix Measurement items and the CFA results

\begin{tabular}{|c|c|}
\hline $\begin{array}{l}\text { Intellectual Capital (Please indicate your degree of agreement with the following statements } \\
\text { describing each aspect of your plant's intellectual capital) }\end{array}$ & Factor loadings ( $\mathrm{t}$ values) \\
\hline Human Capital & $\mathrm{AVE}=0.74, \mathrm{CR}=0.92, \mathrm{Alpha}=0.88$ \\
\hline Employees in this plant are highly skilled in their respective jobs. & $0.857(26.46)$ \\
\hline Employees in this plant are considered among the best people in the organisation. & $0.867(23.00)$ \\
\hline Employees in this plant are experts in their particular jobs and functions. & $0.896(33.09)$ \\
\hline Every employee in this plant has useful experiences. & $0.813(15.82)$ \\
\hline Social Capital & $\mathrm{AVE}=0.72, \mathrm{CR}=0.91, \mathrm{Alpha}=0.87$ \\
\hline There is ample opportunity for informal conversations among employees in the plant. & $0.682(6.91)$ \\
\hline Employees from different departments feel comfortable calling each other when need arises. & $0.896(29.44)$ \\
\hline People are quite accessible to each other in the plant. & $0.915(45.30)$ \\
\hline We are able to discuss problems and tough issues openly. & $0.887(32.28)$ \\
\hline Structural Capital & $\mathrm{AVE}=0.75, \mathrm{CR}=0.92, \mathrm{Alpha}=0.89$ \\
\hline Standard operating procedures are in place. & $0.830(21.88)$ \\
\hline Much of this plant's knowledge is contained in manuals, archives, or databases. & $0.855(22.45)$ \\
\hline We usually follow the sequence of written procedures and rules. & $0.893(32.94)$ \\
\hline Processes in our plant are well defined. & $0.890(32.55)$ \\
\hline $\begin{array}{l}\text { Process Innovation (Please indicate your degree of agreement with the following statements } \\
\text { describing your plant's process innovation) }\end{array}$ & $\mathrm{AVE}=0.73, \mathrm{CR}=0.91, \mathrm{Alpha}=0.88$ \\
\hline We are learning more about the newest processes than our competitors. & $0.859(20.57)$ \\
\hline We are the first within the industry to deploy new processes. & $0.887(32.63)$ \\
\hline We keep up with the latest process developments. & $0.860(20.56)$ \\
\hline We frequently introduce processes that are radically different from existing processes in the industry. & $0.801(14.74)$ \\
\hline $\begin{array}{l}\text { Mass Customisation Capability (Please indicate your degree of agreement with the following } \\
\text { statements assessing your plant's mass customisation capability) }\end{array}$ & $\mathrm{AVE}=0.71, \mathrm{CR}=0.92, \mathrm{Alpha}=0.90$ \\
\hline We are highly capable of large-scale product customisation. & $0.805(13.32)$ \\
\hline We can easily add significant product variety without increasing cost. & $0.834(20.97)$ \\
\hline We can customise products while maintaining high volume. & $0.861(19.10)$ \\
\hline
\end{tabular}


We can add product variety without sacrificing quality.

$0.838(17.06)$

Our capability for responding quickly to customisation requirements is very high.

$0.874(27.11)$

Note: AVE: Average Variance Extracted; CR: Composite Reliability; Alpha: Cronbach’s Alpha; All t values are significant at $\mathrm{p}<0.01$ level. 
Table 1. Demographic information

\begin{tabular}{|c|c|c|c|}
\hline Country & Number of plants & $\begin{array}{l}\text { Plant size } \\
\text { employees) }\end{array}$ & Number of plants \\
\hline Australia & 25 & $<=100$ & 287 \\
\hline China & 100 & $101-200$ & 97 \\
\hline Croatia & 113 & $201-500$ & 132 \\
\hline Hungary & 37 & $501-1000$ & 50 \\
\hline India & 58 & $>1000$ & 77 \\
\hline Ireland & 30 & \multirow[t]{6}{*}{ Total } & \multirow[t]{6}{*}{643} \\
\hline Poland & 79 & & \\
\hline Taiwan & 40 & & \\
\hline USA & 83 & & \\
\hline Vietnam & 80 & & \\
\hline Total & 645 & & \\
\hline \multicolumn{3}{|c|}{ Industry } & Number of plants \\
\hline \multicolumn{3}{|c|}{$\begin{array}{l}\text { Electronic and other electrical equipment and components, except } \\
\text { computer equipment }\end{array}$} & 94 \\
\hline \multicolumn{3}{|c|}{ Food and kindred products } & 66 \\
\hline \multicolumn{3}{|c|}{$\begin{array}{l}\text { Fabricated metal products, except machinery, trailers, and } \\
\text { transportation equipment }\end{array}$} & 98 \\
\hline \multicolumn{3}{|c|}{ Rubber and miscellaneous plastics products } & 47 \\
\hline \multicolumn{3}{|c|}{ Industrial and commercial machinery and computer equipment } & 43 \\
\hline \multicolumn{3}{|c|}{ Miscellaneous manufacturing industries } & 36 \\
\hline \multicolumn{3}{|c|}{ Chemicals and allied products } & 31 \\
\hline \multicolumn{3}{|c|}{ Apparel, other finished products, and textile } & 49 \\
\hline \multicolumn{3}{|c|}{ Primary metal industries } & 28 \\
\hline \multicolumn{3}{|c|}{ Lumber and wood products, furniture } & 43 \\
\hline \multicolumn{3}{|c|}{ Others } & 82 \\
\hline & & Total & 617 \\
\hline
\end{tabular}

Table 2. Descriptive statistics

\begin{tabular}{|l|l|l|l|l|l|}
\hline & HC & SoC & StC & PI & MCC \\
\hline Human Capital (HC) & $\mathbf{0 . 8 6}$ & & & & \\
\hline Social Capital (SoC) & $0.55^{* *}$ & $\mathbf{0 . 8 5}$ & & & \\
\hline Structural Capital (StC) & $0.59^{* *}$ & $0.49^{* *}$ & $\mathbf{0 . 8 7}$ & & \\
\hline Process Innovation (PI) & $0.43^{* *}$ & $0.29^{* *}$ & $0.39^{* *}$ & $\mathbf{0 . 8 5}$ & \\
\hline MC Capability (MCC) & $0.41^{* *}$ & $0.35^{* *}$ & $0.28^{* *}$ & $0.32^{* *}$ & $\mathbf{0 . 8 4}$ \\
\hline Mean & 5.21 & 5.35 & 5.28 & 4.47 & 4.92 \\
\hline Standard deviation & 1.04 & 1.08 & 1.16 & 1.19 & 1.19 \\
\hline
\end{tabular}

Note: $* * p<0.01$; Square root of average variance extracted (AVE) is shown on the diagonal of the matrix in bold. 


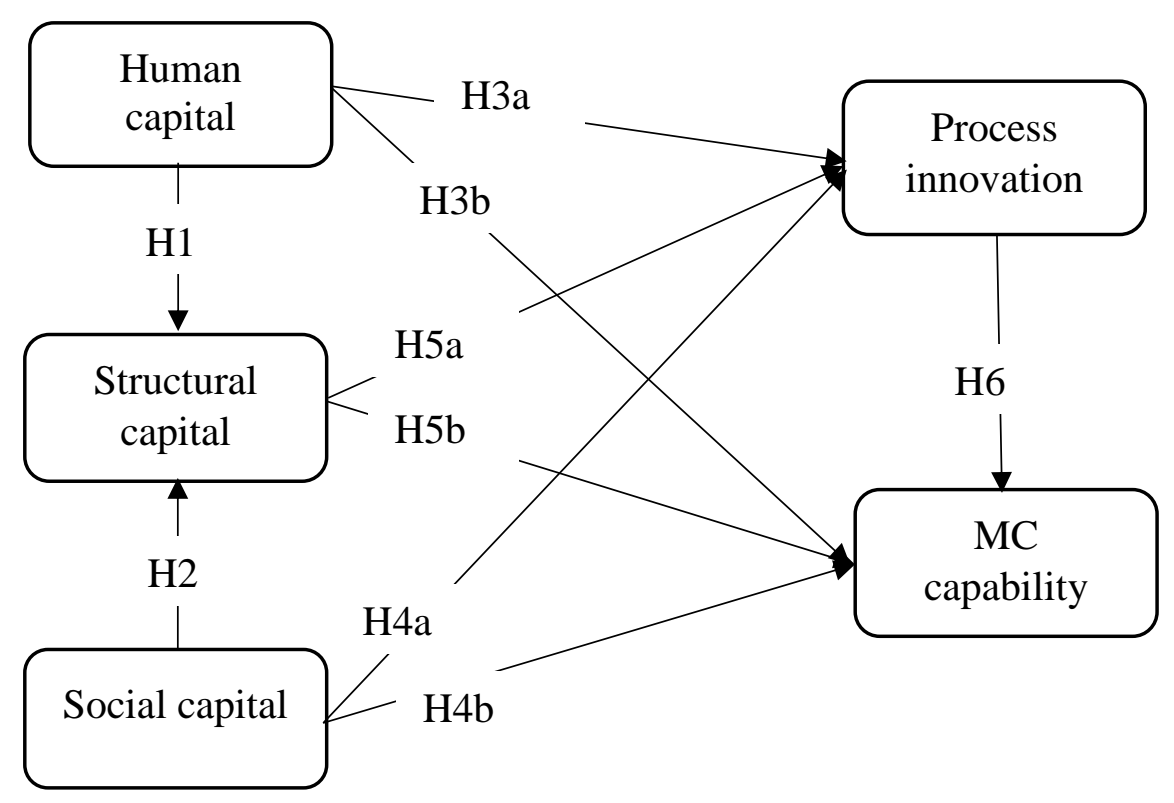

Figure 1. Conceptual framework

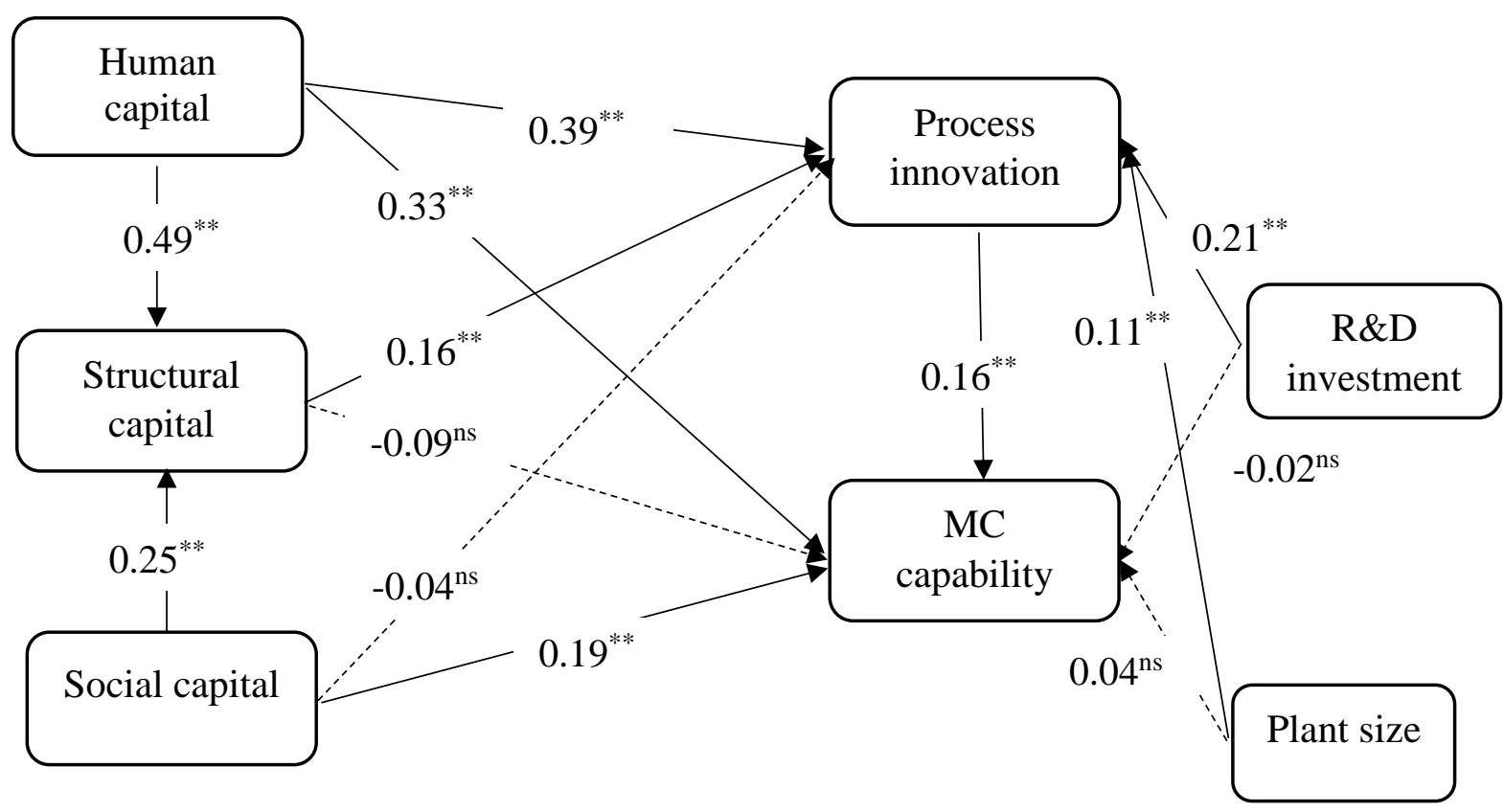

Note: **: $\mathrm{p}<0.01$; ns: not significant

Figure 2. Results of statistical analysis 